\title{
TURISMO: ¿fenómeno postindustrial o mera necesidad básica?
}

\author{
Francisco MUÑOZ DE ESCALONA \\ CSIC (España) \\ franjomues@gmail.com
}

\section{TOURISM: Post-industrial basic necessity or simple phenomenon?}

Resumen: El editor plantea en su invitación una cuestión ardua, la de si el turismo es un fenómeno post-industrial o una necesidad humana básica. Este artículo se propone dar una respuesta razonada a dicha cuestión. En perspectiva, el turismo, por su especial polisemia, puede ser visto, en efecto, como fenómeno social y como necesidad básica, pero sin descarta que sea visto, también, como valioso instrumento para conseguir la paz mundial, como medida eficaz contra el subdesarrollo e incluso como medio para incrementar la propensión al consumo o como medio para recuperar la fuerza laboral gastada en el proceso productivo. También suele ser visto como la primera industria mundial y, a la vez, como la industria que está del lado del hombre. No menos cierto es que esta ambigüedad para definir al turismo obliga a repensar el rol mercantilista de la academia. Al margen del debate, lo que sí podemos adelantar desde ya es que el turismo como fenómeno social es coetáneo de la industrialización, lo que equivale a decir que ni es un fenómeno post-industrial como algunos dicen ni una institución milenaria como otros sostienen.

Abstract: In response to Guest editor who question if tourism is a basic needs or an industry of entertainment, this essay review proposes a new fresh alternative. In perspective, beyond if tourism is a basic needs or a result of post-industrial consumption, the fact is that some specialists believe it represent a peace-keeping mechanism, or as an efficient instrument to accelerate development in third world. The pervasiveness of scholars to define what tourism is represents an effort of commoditizing the academy. Quite aside from this discussion, what we may argue is that tourism as social fact is parallel to the advance of industrialization. Nor tourism is therefore a post-industry, neither an ancient institution as other claim.

Palabras clave: Antropología; Turismo; Solidaridad; Economía

Anthropology; Tourism; Solidarity; Economy 


\section{Introducción}

En el post publicado en boletín-turistico.com el 11 de marzo de 2014(Muñoz de Escalona 2014) se plantea uno de los tópicos más debatidos entre los turisperitos, el de la edad del turismo. Mientras que para unos el turismo existe desde que existe la especie humana, para otros el turismo es cosa reciente. Mientras que para los primeros el turismo tendría dos millones y medio de años para los segundos tiene poco más de medio siglo. A la vez que algunos proponen que el turismo consiste en desplazarse por el territorio, algo así como lo que hacen los nómadas, para otros el turismo no sería nada sin la existencia de una compleja y voluminosa industria al servicio de una demanda igualmente compleja y masiva, la de los veraneantes. Hay quienes acuden a la antropología, a los idiomas extintos o a la mitología para formular tesis explicativas de la aparición del turismo como fenómeno social. Ante tanta diversidad de criterios poco podría hacerse para poner de acuerdo a unos y otros sobre la época en la que surge el turismo, o para formular una explicación convincente y compartida sobre su existencia.

Sin embargo, contra los primeros cabe aportar que para ser turista no basta con hacer desplazamientos, además de desplazarse habría que pertenecer a una sociedad sedentaria, un tipo de sociedad cuyos comienzos se remontan nada menos que al Neolítico, hace de eso entre unos diez y doce mil años. Pero siendo esta una condición necesaria no parece que sea suficiente. Si los viajes de ida y vuelta (turísticos según manda la etimología) son caros, sobre todo cuando no hay servicios facilitadores abundantes y baratos, para hacerlos es preciso que haya sociedades ricas en las que la riqueza sea tal que pueda quedar un remanente de recursos para gastar en viajes después de cubrir las necesidades más urgentes. De aquí que para fijar una edad verosímil haya que contestar a esta pregunta: ¿Cuándo surgieron las sociedades opulentas? De la respuesta a la pregunta depende, a su vez la respuesta a la cuestión que nos ocupa. ¿Pero, bastaría con que hubiera en las sociedades ricas minorías opulentas? Podría parecer que la respuesta es positiva, pero algo nos dice, en favor de quienes piensan que el turismo es un fenómeno reciente, que para que haya turismo tiene que haber sociedades en las que la opulencia sea compartida por una cantidad significativa de personas. Dicho de otro modo: la existencia de sociedades ricas con pocos miembros opulentos y muchos desfavorecidos no podría dar lugar al turismo como fenómeno social aunque hubiera individuos en condiciones de "hacerlo". Si lo hacían porque para ellos era una necesidad básica es algo que aún no podemos dirimir y por ello tenemos que posponerlo para más adelante. De momento, se impone formular la siguiente pregunta:¿Cuando, donde y como hubo sociedades ricas con clases sociales opulentas en número significativo?

Por consiguiente, la tarea del investigador consiste en averiguar en qué momento surgieron las sociedades ricas con distribución desigual de la riqueza y en qué momento aparecieron sociedades con clases con recursos excedentes después de cubrir las necesidades vitales en número significativo. Para averiguar cuando, donde y como acontecieron estas emergencias no tenemos más remedio que apoyarnos en la historia económica y en la antropología cultural.

\section{La polisemia del turismo}

Ríos de tinta se derramaron durante años sobre la espinosa cuestión de quién podía ser tenido por turista y sobre quién no podía nunca blasonar de merecer tan meritoria consideración. La necesidad de contar con unas estadísticas veraces sobre la demanda se hizo patente de cara a las inversiones en la industria hotelera. Lo mismo cabe decir del concepto de turismo y de su verdadera naturaleza. La famosa frase de Paul Bernecker (1964), a mediados del siglo XX, de que hay tantas definiciones de turismo como tratadistas se dedican a él refleja 
esta atípica situación. No obstante, en la segunda mitad del pasado siglo, el calor del debate se fue enfriando; al principio tímidamente para luego, de golpe, ir desapareciendo hasta el punto de que en nuestros días ya no parece contar con el interés de nadie.

Lo cual no quiere decir que las razones para el mantenimiento de aquellos agrios debates hayan sido resueltas satisfactoriamente porque lo cierto es que se llegó a un cierto cansancio y, sobre todo, al convencimiento de que se trataba de una vía muerta que convenía abandonar. Hubo quien sostenía con cierto candor que la solución a la incógnita vendría por sí sola en tanto se hicieran los trabajos de campo que según ellos hay que hacer sin descanso porque lo empírico debe erradicar lo especulativo. ¿Ignoran quienes así pontifican que no hay investigación empírica correcta si antes las nociones teóricas no han quedado meridianamente bien formuladas?

Como nosotros no lo ignoramos es por lo que hemos decidido traer de nuevo a colación aquel viejo y abandonado debate y plantear de nuevo la persistente cuestión de la polisemia tanto de la voz como del mismo concepto de turismo. Se trata, pues, de un pretexto aparentemente menor pero que guarda en su seno las ascuas, aun ígneas por mal apagadas, de las viejas discusiones de antaño, ascuas que iluminan unas sombras que permanecen intactas bajo dos cuestiones tan olvidadas como básicas:

1: seguimos sin conocer la verdadera identidad del turismo.

2: el turismo es multifacético, es decir, inevitablemente polisémico.

Cuestiones ambas que, paradójicamente, vienen a equivaler a la persistencia de aquellas sombras que, aunque arrumbadas en el trastero de los objetos en desuso, necesitan a nuestro juicio ser sacados a flote cuanto antes en aras de la construcción de un conocimiento que sea sólido y de una aplicación eficaz al servicio de la creación de riqueza. Mientras la polisemia no deje paso a la construcción de un concepto claro de la noción de turismo cada cual está autorizado a sostener el que mejor se preste a sus intenciones y necesidades.

\section{A la luz de la antropología cultural}

Empecemos por consultar con la antropología, una ciencia que debe mucho al alemán residente en USA Franz Boas, conocido y valorado por sus trabajos sobre los indios kwakiutl del norte de Vancouver (Canadá), trabajos que le llevaron a establecer un nueva teoría de cultura y raza con la que desarrolló una de las más influyentes corrientes antropológicas: el llamado relativismo cultural, basado en la tesis de que todos los sistemas culturales tienen el mismo valor, es decir, que no hay lo que llamamos culturas primitivas sino culturas diferentes. Las diferencias entre ellas no son más que el resultado de sus propias condiciones históricas, sociales y/o geográficas, lo que lleva a superar los planteamientos de las escuelas de la difusión y de la evolución. Boas puso sobre la mesa el estudio de la cultura kwakiult pero, debido a su empirismo a ultranza, se limitó a ofrecer una mera descripción de sus costumbres (Harris, 1988). En sus célebres cuadernos de campo anotó el resultado de sus minuciosas observaciones, un método que consideraba como la forma más eficaz de avanzar en el conocimiento de las sociedades habida cuenta de que rehusaba la especulación, es decir, la formulación de hipótesis previas a la investigación científica. Por esta razón, sus aportaciones aumentaron espectacularmente la información sobre la realidad pero no lograron establecer una explicación de la misma.

Hubo que esperar a la aparición del Essai sur le don. Forme et raison de l'échangedans les societésarchaiques), la obra del francés Marcel Mauss, publicada en 1924, en la que se estudian los peculiares métodos de intercambio en las sociedades arcaicas. Mauss fue el padre de la antropología económica al mostrar que el don o regalo es básico en tales sociedades en la medida en que el vínculo no mercantil de los intercambios (regalo) obliga social 
y rígidamente a los receptores a responder con otro regalo con la condición de que tenga un "valor" superior al recibido. Georges Bataille se basó en los aportes de Mauss para desarrollar lo que se ha llamado una economía generalizada, basada en la abundancia de energía/ materia en la Tierra. Citamos por el artículo La notion de depènse publicado en 1932 por la Critique Social, en el cual expuso por primera vez su original pensamiento bajo la impresión que le causó oír unas conferencias de Mauss:

"Opuesta a la noción artificial de trueque, la forma arcaica del intercambio ha sido identificada por Mauss con el nombre de potlatch, tomado de los indios del noroeste americano, que practican el tipo más conocido. Instituciones análogas al potlatch indio o rastros de ellas han sido halladas con mucha frecuencia. El potlatch de los tlingit, los haïda, los tsimshian, los kwakiutl de la costa noroeste ha sido estudiado con precisión desde fines del siglo XIX (pero no fue comparado, entonces, con las formas arcaicas de intercambio de otros países). Los pueblos americanos menos avanzados practican el potlatch con ocasión de cambios en la situación de las personas -iniciaciones, matrimonios, funerales e incluso, bajo una forma menos desarrollada, nunca puede ser disociado de una fiesta, bien porque el potlatch ocasione la fiesta, bien porque tenga lugar con ocasión de ella. El potlatch excluye todo regateo y, en general, está constituido por un don considerable de riquezas que donadas de manera ostensible con el objeto de humillar o desafiar a un rival el cual queda por ello obligado a responder con una donación posterior. El carácter de intercambio del don resulta del hecho de que el donatario, para evitar la humillación al aceptar el desafío viene obligado a responder con un don más importante; es decir, que debe devolver con el valor recibido aumentado (interés)".

Pero el don no es la única forma del potlatch. Es igualmente posible desafiar rivales por medio de destrucciones espectaculares de riqueza. A través de esta última forma es como el potlatch incorpora el sacrificio religioso, siendo las destrucciones teóricamente ofrecidas a los ancestros míticos de los donatarios. En época relativamente reciente podía acontecer que un jefe tlingit se presentara ante su rival degollando en su presencia a algunos de sus esclavos. Esta destrucción debía ser respondida, en un plazo determinado, con el degollamiento de un número de esclavos mayor. Los tchoukchi del extremo noroeste siberiano, que conocían instituciones análogas al potlatch, degollaban colleras de perros de gran valor para hostigar y humillar a otros grupos. En el noroeste americano, las destrucciones consisten incluso en incendios de aldeas y en el destrozo de pequeñas flotas de canoas. Lingotes de cobre blasonados, una especie de moneda a la que se atribuía un valor tan alto que representaban una inmensa fortuna, eran destrozadas o arrojadas al mar. El delirio propio de la fiesta se asocia también a las hecatombes de patrimonio e incluso a los don es realizado con intención de maravillar y sobresalir (Muñoz de Escalona 1987: 32-33).

Habrá que pedir disculpas al lector por una cita inusualmente extensa pero pensamos que queda justificada porque es la forma más directa y completa de exponer la concepciónbatailleana de una institución tan peculiar como el potlatch, término que ha sido adoptado por la ciencia como genérico para designar su inquietante complejidad. Años más tarde, con motivo del Plan Marshall, Bataille desarrolló el pensamiento expuesto en La notion de depènse y acometió un proyecto de suma envergadura que fue iniciado con La parte maudite, publicada en 1949, la primera parte de lo que sería una ambiciosa teoría sobre la sociedad nucleada por su concepción de la soberanía perdida por el ser humano en el momento de diferenciarse de la animalidad. La segunda parte de la trilogía,El erotismo vio la luz en 1957. El erotismo es considerado en ella como una forma paradigmática de la pérdida ritual que establece la institución del potlatch. Ese paradigma queda encarnado para Bataille por el erotismo no 
reproductivo. La tercera y última parte quedó inconclusa. Para comprender en profundidad la propuesta de Bataille hay que recordar que el planeta Tierra recibe un flujo de energía solar gratuito, es decir, a cambio de nada, lo que equivale a que nuestro planeta soporta un problema de abundancia de recursos en la medida en que, de acuerdo con Einstein, la materia (masa) es igual a la velocidad de la luz al cuadrado. Dicho de otra forma: el problema de la humanidad no sería la escasez sino la abundancia y, en consecuencia, después de quedar cubiertas las necesidades vitales, queda siempre un remanente de energía-materia que obliga a consumirla (dilapidarla) lúdicamente, si no queremos que la presión de ese excedente termine por provocar catástrofes desastrosas como guerras, huelgas, hecatombes, incendios y otras formas de pérdida de riqueza traumáticas. De modo que o la humanidad gasta el excedente (la parte maldita) de un modo gratificante o la presión que ejerce se liberará, ineluctablemente, de forma dolorosa.

La parte maudite, después de estudiar el potlatch originario, se ocupa de otros modelos de sociedad basados en diferentes formas de dilapidación (gasto improductivo) del excedente. Las sociedades estudiadas por Bataille son, por este orden, la azteca, la pre-islámica y la tibetana. Después de ocuparse de ellas, el autor estudia a la luz de su teoría los modelos sociales que se basan en el aumento intencionado o no de la riqueza por medio del gasto productivo, dedicando especial atención a la sociedad islámica y a las sociedades modernas, todas ellas calificadas de sociedades empresariales. La sociedad empresarial islámica se dedicó a la expansión territorial de la fe musulmana. Las sociedades empresariales modernas se basan en el ahorro compulsivo (austeridad a ultranza) financiador de la inversión, un ahorro que es voluntario en las mercantiles (capitalistas), y obligado en las sociedades de planificación central (soviéticas). De acuerdo con el pensamiento batailleano, la materia (riqueza) es una consecuencia obligada del movimiento natural de la energía en la superficie de la Tierra. Plantea así el autor las bases de la economía general, en la que la riqueza (producción) está garantizada pero no así el gasto, es decir, el consumo de la riqueza, o mejor, la consumición (destrucción), término más expresivo que consumo ya que el consumo puede ser tanto destructivo o improductivo (consumo final en la cobertura de las necesidades vitales) como productivo, el que se realiza para aumentar sostenidamente la capacidad de producción.

A la luz de esta peculiar y sin duda asombrosa teoría, Bataille detecta la existencia de sociedades arcaicas que padecen el problema de la acumulación de riqueza y por ello cabe considerarlas como sociedades opulentas. Unas solucionan el problema por medio de la institución del potlatch (potenciación del gasto improductivo, lúdico-fiestas - o violento lucha, violencia -, pero otras, como las que se basan en el ahorro y la inversión, en vez de solucionarlo lo agravan en la medida en la que aspiran al aumento sostenido de riqueza. A estas nos referiremos en el siguiente apartado. Ahora debemos detenernos en las sociedades arcaicas con potlatch pues su análisis a la luz de la teoría del excedente (parte maldita o gasto improductivo) nos puede permitir averiguar si contaban con una institución como el turismo.

Los estudiosos de la cultura del potlatch coinciden en reconocer que dicha cultura la desarrollan sociedades ricas en el sentido establecido y que gastan una parte significativa de sus recursos en las prácticas propias de dicha institución, consistentes, como ya hemos visto, en la celebración de fiestas colectivas durante las cuales tenía lugar el intercambio de donaciones rituales de recursos e incluso la destrucción de embarcaciones y el sacrificio de esclavos, donaciones y destrucciones que, como ya se ha dicho, obligaban al receptor a responder con otras donaciones siempre que fueran de valor superior. Como tales rituales se celebraban en lugares alejados de su residencia, ello apunta a que se hacían viajes de ida y vuelta que obligaban a nuevos viajes para responder a las donaciones recibidas. Si por turismo entendemos la realización la realización de desplazamientos circulares masivos con motivos festivos habrá que reconocer que estas sociedades practicaban el turismo. No obstante, 
si nos atenemos a la condición que para esta práctica establece la turispericia, la de que estos desplazamientos sean voluntarios, es decir, autónomos, habrá que diagnosticar que esos viajes no pueden ser tenidos como turismo en la medida en que su realización obedecía a una obligación social inexcusable. La mentada polisemia es la razón de que para unos el potlatchpueda ser considerado como turismo mientras que para otros no lo sea en absoluto a pesar de ser desplazamientos circulares, festivos y masivos. La institución del potlatch, pues, podría ser interpretada como una forma de turismo arcaico, pero es que incluso si reparamos en su componente de obligación social podría ser vista como la satisfacción de una necesidad básica. No obstante, no cabe la menor duda de que ambas consideraciones suponen un forzamiento inusitado de la función social que cumple el potlatch al asimilarlo al turismo como fenómeno o como necesidad.

Para terminar convendría hacer una referencia al jugo y para ello nada más indicado que recurrir a la conocida teoría de Huizinga es que en el juego se encuentra la raíz del desarrollo cultural por lo que, a su juicio cumple una función humana tan esencial como el trabajo y la investigación científica. Se desvía así del pensamiento marxista, para la cual las sociedades humanas construyen su medio vital por medio de la actividad laboral según sus específicas relaciones de producción. Como se sabe, en una de las visiones del turismo, la hegemónica, lo lúdico constituye su esencia hasta el punto de que turismo y ocio han llegado a ser sinónimos. Por ello, de ser correcta la teoría lúdica de Huizinga, podemos afirmar que las sociedades con potlatch tenían turismo. Como ya hemos dicho, el potlatch es una fiesta y un juego que exige desplazarse al lugar en el que tendrá lugar el intercambio de unos bienes en un momento por otros en el futuro con valor superior al recibido que algunos confunden con la usura. Ahora bien, por muy esencial que algunos presenten lo lúdico en el desarrollo del turismo no hay que olvidar que ha de ir acompañado de desplazamientos circulares. Que haya sociedades que practican el juego en su lugar de residencia permanente no permite suponer que en ellas haya turismo. Por la misma razón, aun a pesar de que haya sociedades que realicen desplazamientos circulares con determinados motivos, si esos motivos, aunque hoy puedan parecerlos, no son lúdicos, no se puede sostener que en ellas haya turismo si admitimos que turismo y ocio han de ir unidos. No todo lo que parecen actividades lúdicas en las sociedades antiguas debe ser considerado como lúdico en sentido moderno. Hay quien así lo cree como es el caso de Maximiliano Korstanje(2014), para quien el origen del turismo se encuentra en la mitología nórdica y en las antiguas culturas griega y romana. Para Korstanje, en ellas había turismo porque había villas de recreo y gran afluencia de espectadores a los juegos olímpicos o a los que tenían lugar en el Coliseum, aunque habría que documentar que las distancias recorridas fueran notables. Por otra parte es cierto que desde tiempos inmemoriales se visitaron las casas de cura (Kurort), lo baños termales y los santuarios, a veces desde lugares distantes, pero habría de demostrar que las visitas eran masivas y que estaban motivadas por el ocio, la curiosidad o la diversión, no por la curación, la fe o el cumplimiento de alguna obligación social inexcusable. El tema central de la discusión radicatanto en la supuesta masividad del turismo como en la existencia de equipamientos ad hoc dotados de gran capacidad de acogida. Porque es obvio que los desplazamientos y estancias temporales han de ser masivos si queremos tenerlos como constitutivos de turismo como fenómeno social, incluso si deflactamos el sentido de lo masivo teniendo en cuenta las menores poblaciones del pasado. Pero más adelante volveremos sobre estas cuestiones. Consecuentemente, para que puedan ser tenidos estos desplazamientos circulares y supuestamente lúdicos como la forma de satisfacer una necesidad básica habría que demostrar que fueran voluntarios y de que de su realización dependa la supervivencia.

\section{A la luz de la economía}

En este avatar nos puede ser de utilidad la ayuda de uno de los más destacados conoce- 
dores de la historia social. Nos referimos a Eric John Ernest Hobsbawm, fue un historiador judío y marxista. Está considerado como el pensador clave de la historia moderna. Es el autor de varias obras esclarecedoras de nuestro pasado. De ellas debemos resaltar cuatro: The Age of Revolution 1789-1848, que apareció en 1962, publicada en español como Las revoluciones burguesas, The Age of Capital 1848-1875, publicada en 1975, en español como La era del capitalismo y The Age of Empire 1875-1914, publicada en 1987 y en español como La era del imperio. La serie terminó en 1998 con The Age of Extreme, en español Historia del siglo XX. Para la cuestión que tratamos de resolver nos bastan las dos primeras. En la primera se nos muestra la historia de Europa entre dos revoluciones, la francesa de $1789 \mathrm{y}$ la europea de 1848. En esos 59 años nació, creció y se consolidó la clase burguesa como consecuencia de otra revolución, la revolución industrial que tuvo lugar en el Reino Unido como consecuencia de la aplicación de la fuerza del vapor a las actividades productivas. La nueva clase burguesa aportó la idea innovadora de que el desarrollo de la riqueza depende de las empresas privadas y de la competencia entre ellas, de forma que el abastecimiento de todo lo necesario se hace a través del mercado, incluida la mano de obra. El mercado permite comprar insumos baratos y vender la producción a precios que cubren los costes y dejan un beneficio para el empresario. La revolución industrial se originó en Gran Bretaña mientras la revolución burguesa tuvo lugar en Francia, pero, en poco tiempo, ambas revoluciones se difundieron primero por Europa y luego fuera de ella dando lugar a una nueva clase social, basada en una clase media fundada en la meritocracia. Un historiador francés llamó a la nueva clase "la burguesía conquistadora", detrás de la cual se hallaban las masas siempre dispuestas, dice Hobsbawm, a convertir en sociales los avances en el desarrollo económico.

La segunda etapa de este proceso tuvo lugar a partir de la revolución popular de 1848, a la que se llamó la primavera de los pueblos, una revolución que fracasó a pesar de su difusión por numerosos países. Su fracaso dio paso una espectacular transformación económica basada en un aumento de la riqueza no conocido hasta entonces pero que entró en crisis hacia 1875. Fue un cuarto se siglo durante el cual el mundo se hizo capitalista y una significativa minoría de países "desarrollados" se transformaron en economías industriales. El capital era barato lo que invitaba a invertir en nuevos negocios. El rápido aumento de los precios de los productos industriales propició un esplendor económico hartamente satisfactorio para los negociantes ávidos de ganancias. La aplicación del vapor fue más allá de la industria transformadora y propició la llamada revolución de los transportes. El ferrocarril y la navegación a vapor pusieron en marcha lo que ya entonces se percibía como un mercado mundial tanto para abastecerse de materias primas como para vender productos terminados. La mejora de los medios de transporte en confort, velocidad y capacidad pronto se aplicó al transporte de viajeros consiguiendo con ello lo que los alemanes llamaron el vencimiento de la distancia (Verkehr). Las ciudades europeas mejoraron su accesibilidad y con ellos aumentaron espectacularmente las llegadas de forasteros (Fremden).

La masificación de estos flujos en algunas de ellas recibió el nombre de Fremdenverke$h r$, expresión que pronto fue sustituida por un neologismo, turismo, y con él se dio nombre a un nuevo fenómeno social. Con esta creciente demanda inducida de viajes de todo tipo pero sobre todo por gusto se pudieron aprovechar los excedentes de capacidad de las crecientes inversiones mundiales en ferrocarriles y en navegación marítima y fluvial. Pronto se desarrolló un nuevo negocio basado en fuertes inversiones en servicios de hospitalidad (alojamiento y refacción), completando así lo que los turisperitos llaman industria turística, un nuevo sector de la actividad productiva poco desarrollado hasta entonces, el cual terminó rebasando su carácter complementarias para convertirse en una pujante industria, que con el tiempo se puso en plano de igualdad con las demás industrias como fuente de desarrollo económico generalizado.

Pero podemos abandonar el campo de lo sociológico y macroeconómico para instalarnos 
en el campo de lo personal y microeconómico. La doctrina convencional del turismo se basa, como sabemos, en el estudio dela conducta observable del turista. Para la convención, el turista sale de su domicilio para visitar uno o varios lugares por ocio, curiosidad, distracción o descanso. Si seguimos observando minuciosa y detalladamente tal conducta como establece la visión convencional, constatamos que el turista utiliza medios de transporte para desplazarse y medios de hospitalidad para alojarse y refaccionarse en el lugar o lugares visitados, lugares que ha elegido porque en ellos hay monumentos, paisajes, espectáculos, exposiciones, etc. Este enfoque lleva a enumerar y cuantificar los efectos que tienen lugar en los lugares visitados como consecuencia de las relaciones que tienen lugar entre los residentes y los visitantes, efectos entre los que se destacan muy especialmente los que se derivan de las relaciones de intercambio mercantil entre ellos, lo que lleva a una investigación que cae en el campo de la sociología y en el de la macroeconomía. Lo personal no observable y lo microeconómico quedan fuera de ella. Si queremos tenerlos en cuenta no tenemos más remedio que cambiar el enfoque convencional y sustituirlo por otro capaz de sacar a la luz la conducta del turista que pasa inadvertida pero que es condicionante. Para ello tenemos dos vías diferentes pero conducentes al mismo resultado:

Vía 1. Programa de desplazamiento circular. Todo aquel que quiere salir fuera de su domicilio planifica o programa su salida y su regreso fijando, entre otras cosas, el lugar o lugares a los que se propone ir, los servicios logísticos (facilitadores)que utilizará y las actividades que desarrollará durante su estancia pasajera propiciadas por servicios ad hoc (incentivadores). El programa puede ser elaborado por el mismo sujeto o por un tercero con o sin afán de lucro. En ambos casos, el programa tiene la consideración de un producto (servicio) bien identificado según sus características propias y elaborado con otros productos (servicios) según una tecnología específica.

Vía 2. Programa de visita. Cuando el turista se encuentra en el lugar seleccionado se dispone a consumir numerosos servicios (logísticos o facilitadores y servicios ad hoc o incentivadores) pero todos ellos integrados en un programa de visita elaborada de acuerdo con un diseño previo, programa que será "abierto", si lo elabora él mismo o "cerrado", si lo elabora un tercero con o sin afán de lucro. En ambos casos, el programa tiene la consideración de un producto (servicio) bien identificado según sus características propias y elaborado con otros productos (servicios) según una tecnología específica.

Ambas vías conducen, como decimos al mismo resultado y ponen en evidencia algo que, si bien no es directamente observable, revelan conductas que pasan inadvertidas por la convención, pero que se pone de manifiesto gracias a la ayuda de una teoría bien contrastada, la teoría económica. Para el análisis económico es imprescindible identificar con precisión el bien o servicio que satisface cualquier necesidad sentida por el consumidor. El turista es, sin duda, un consumidor, más aun, es el paradigma del consumidor, como no se cansaron en insistir Hunziker y Krapf (1942). Según los economistas citados, el turista es un consumidor, jamás un productor (pues ha dejado de serlo durante sus vacaciones) de un conjunto heterogéneo, amorfo y variable de bienes y servicios que, aunque susceptibles de ser tratados por la sociología, no lo son por la economía de un modo satisfactorio, habida cuenta de que no quedan objetivamente identificados ni el bien o servicio turístico ni la empresa que lo produce (turística). Este grave obstáculo queda salvado en cuanto definimos el bien o servicio turístico como el programa de desplazamiento circular (vía 1) o el programa de visita (vía 2). La aceptación de esta definición del turismo permite llevar a cabo la investigación en el campo de la microeconomía, un campo que complementa adecuadamente al 
campo sociológico/macroeconómico convencional enriqueciendo así de forma convincente el conocimiento de la realidad.

De acuerdo con lo expuesto, en lo que concierne al objeto que nos ocupa, el de las edades del turismo, gracias al enfoque alternativo es posible sostener que el turismo existe desde que el ser humano se hizo primero sedentario, hace diez o doce mil años, para desarrollar posteriormente, civilizaciones o culturas urbanas hace unos cinco mil años. El desarrollo de asentamientos urbanos fue el efecto (y la causa) de la aparición de sociedades ricas aunque solo fuera porque en ellas había clases opulentas. Clases que acaparaban grandes riquezas y por ello podían sentir la necesidad de salir al exterior motivadas por necesidades muy variadas. Para ello debían disponer de programas de desplazamiento circular con toda seguridad elaborados por sus servidores.

En consecuencia es posible sostener que desde hace cinco mil años se elaboraron y ejecutaron (consumieron) programas de desplazamiento circular o, en otras palabras, viajes turísticos con motivos básicamente heterónomos. Durante milenios esta situación se mantuvo sin cambios hasta llegar al siglo XVIII. Hasta entonces se constata la existencia de viajes turísticos, pero no de turismo. A partir de entonces, ya en el siglo XIX, surge la realización masiva de viajes turísticos, es decir, el turismo como fenómeno social. El tour precede al tourism como el consumo precede al consumismo y el automóvil al automovilismo. Sin tour no hay turismo pero para que haya turismo es preciso que la práctica del tour sea masiva.

Después de lo dicho parece que podemos sostener con firmeza que los viajes de ida y vuelta han existido desde hace miles de años pero que el turismo apareció como consecuencia del desarrollo capitalista: El turismo es, pues, un hijo ilegitimo del capitalismo: nació del primer capitalismo a mediados del siglo XIX, se vio como una forma de aumentar el consumo en general y de los medios ferroviarios de transporte en particular y se ha legitimado por su larga permanencia en el tiempo. Su futuro está sin duda tan asegurado como lo está el capitalismo, ambos dotados de una tan excepcional versatilidad que siempre acaban por renacer de sus propias cenizas.

\section{A modo de resumen y conclusiones}

Entre las múltiples razones por las que los turisperitos están convencidos de que el turismo es una realidad dotada de una extremada complejidad se encuentra el que aún no se haya conseguido averiguar por qué razón el hombre, y la mujer, buscan denodadamente la distracción, la recreación y la diversión. En resumidas cuentas, que buscan el ocio porque lo necesitan. La cuestión está en saber por qué lo necesitan. El Génesis nos dio una razón hace miles de años. En ese viejo libro se nos asegura que Dios creó al hombre y a la mujer y les dio como hábitat el Paraíso, un lugar en el que la vida era distendida y la problemática, en el que todo lo creado estaba al servicio de nuestros primeros padres. Todo menos los frutos de un árbol, pero que la desobediencia de esta prohibición les supuso la expulsión de ese mundo de felicidad y de ocio y también la obligación de trabajar para subsistir. La visión bíblica da una respuesta a la cuestión de por qué los hombres y las mujeres aman el ocio, y esa respuesta no es otra que porque lo perdieron. No obstante, después de Charles Darwin esa visión ha quedado cuestionada. La vida se desarrollas desde las formas de vida más simples (las células) hasta las más evolucionadas, los mamíferos superiores, entre los cuales se encuentra el hombre. Como la de todos sus ancestros la vida del hombre se desarrolla en medio de la ley de la depredación generalizada, la cual exige instintos pero también esfuerzo, es decir, trabajo, justo lo contrario del ocio. El trabajo de los hombres, como el de los mamíferos superiores, se lleva a cabo por medio de desplazamientos por el territorio, primero de forma nómada y más recientemente, de forma sedentaria.

¿Practicaban los hombres primigenios el ocio? Huizinga (1938) de quien ya hemos hablado, sostiene que, como demás los mamíferos, el hombre es un animal lúdico. El juego es 
considerado un fenómeno cultural, pero no solo en sus aspectos biológicos, psicológicos o etnográficos, sino que supone una función humana tan esencial como la reflexión y el trabajo. El juego es visto así como el origen de la cultura. En sus propias palabras: "Porque no se trata, del lugar que al juego corresponda entre las demás manifestaciones de la cultura, sino en qué grado la cultura misma ofrece un carácter de juego". Lo que no se plantea Huizinga es la posibilidad de que el juego sea la actividad que los animales superiores desarrollan desde sus primeros años de vida para prepararse para no perecer y para vivir en el seno de la depredación. Podemos interpretar las carantoñas y los revolcones de los retoños de los tigres como juegos pero lo más verosímil es que esas actividades sean entrenamientos instintivos de preparación pata la vida adulta. La aspiración a la prácticas de los juegos en la especie homo puede por ello ser vista bajo este mismo prisma. Las justas y los torneos medievales son actividades que pueden ser vistas como lúdicas pero también como preparación para la guerra, con lo que la función del juego (ocio) pasa a ser tributaria de la noción del trabajo (negocio).

Dicho lo que antecede, puede que ni el hombre haya vivido desde sus orígenes una vida ociosa y que la perdiera por desobediencia ni que el juego cumpla la función básica que sin duda corresponde al trabajo como sostiene un destacado coetáneo de Charles Darwin, Carlos Marx, en la vida humana y en su desarrollo desde las fases iniciales hasta las actuales.

De modo que la cuestión de por qué el hombre aspira al ocio y a la diversión sigue sin ser resuelta. Hay, no obstante, opiniones diversas. Lo que parece cierto es que las clases gobernantes de las primeras civilizaciones urbanas (políticas) cayeron en la cuenta de que las masas no solo quieren pan, también quieren circo. ¿Quiere esto decir que las distracciones son tan necesarias como los alimentos para los hombres? Porque de ser así, el turismo como forma de distracción, sería una necesidad básica. Aunque no cabe descartar que las distracciones, al menos las organizadas, hayan sido más una necesidad gubernamental más que una necesidad vital. Y si abandonamos las civilizaciones de la antigüedad y nos ocupamos de las modernas, los juegos y las distracciones, y con ellos el turismo, se comporten en la misma onda de la antigüedad aunque convenientemente actualizada y adaptada. El secreto del desarrollo económico radica en la inversión, pero la inversión es consumo, no consumo final sino intermedio, un consumo de recursos con la finalidad de aumentar la capacidad de producción del sistema, el cual consigue tales volúmenes de productos que han de ser consumidos finalmente, es decir, destruidos, habida cuenta de que han de desaparecer para que se pueda seguir produciendo. La producción necesita la consumición como la consumición necesita la producción. En otras palabras: la producción trata de cubrir las necesidades pero al mismo tiempo que las satisface crea necesidades nuevas. El turismo es una de esas necesidades nuevas, una necesidad que bien puede ser vista como vital para el hombre pero también como una forma de recuperar las energías perdidas en el sistema productivo con el fin de mantenerlo y restaurarlo en un proceso inacabable. Un proceso que, al decir de los ecologistas, puede acabar con la vida en el planeta Tierra. Pero esta es ya otra enojosa cuestión.

\section{Referencias}

BATAILLE, G.

1932 La notion de depènse. La Critique Social. Revista de pensamiento marxista de orientación trotskista. Paris (ver la versión española, Icaria, Barcelona, 1987)

1949 La parte maudite. Paris: Les Editions de Minuit (ver la versión española de F. Muñoz de BERNECKER, P. Escalona: La parte maldita precedida de La noción de gasto. Icaria, Barcelona, 1987)

1964 Les fondements du tourisme. Cours d'etudes touristiques Ginebra: UIOOT.

BOAS, F

1897 The Social Organization and Secret Societies of the Kwakiutl Indians. Report of the U.S. 
HARRIS, M

National Museum for 1895: 311-738

1988 Introducción a la antropología general. Madrid: Alianza Universidad HOBSBAWM, E. J.:

1962 Las revoluciones burguesas. Madrid: Crítica

1975 La era del capitalismo. Madrid: Guadarrama

HUIZINGA, J.

$2000 \quad$ Homo ludens. Madrid: Alianza

HUNZIKER, W y KRAPF, K.

1942 Gründriss der algemeinen Fremdenverkehrslehre. Polygraphicher Verlag. Zurich KRAPF, K.

1949 "Quelques precisitions sur la notion de tourisme", Revue de Tourisme, 2: 41-44 (Berna) KORSTANJE, M.

2014 "Teoría Turística: el nacimiento de la plataforma instrumentalista". En F. M. Escalona (Edit.). Movilidad y miradas turísticas: 19-42). Saarbrücken: Editorial Académica Española.

MAUSS, $\mathrm{M}$.

2009 Ensayo sobre el don, forma y función del intercambio en las sociedades arcaicas. Madrid, Katz.

MORGENROTH, K

1959 "La signification de la science du tourismepour la pratique du tourisme", Revue de Tourisme, 4: 174-182.

MUÑOZ DE ESCALONA, F.

2011 Autopsia del turismo. Saarbrücken: Editorial Académica Española.

2014 Blog Removiendo aguas del turismo. Capitalismo y turismo: una relación paternofilial. En www.boletin-turistico.com 